\title{
Comments Made in Response to "Studying Intercollegiate Sports: High Stakes, Low Rewards" by Dr. Jay Coakley
}

\author{
John P. Evans
}

In his talk, Jay Coakley offered valuable observations on the prospects for quality scholarship on intercollegiate athletics. He spoke from the perspective of his own academic discipline and background, as well as his own experience and observation. We owe him our thanks for organizing these thoughts for our consideration.

My response is organized into four brief segments:

1. A high-level summary of what I take Jay's message to be,

2. Some observations from my perspective as a Faculty Athletics Representative based on involvement in NCAA work,

3. An experience in which I participated that shared a number of characteristics that Jay noted in his talk, and

4. A related development that has been influenced by factors similar to those cited by Jay.

To look ahead to my bottom line, despite the appropriate concerns that Jay noted, I find some basis for optimism concerning the prospect of careful and valuable scholarship focused on intercollegiate sports. I should note here that I regard the publication of quality scholarly work on sports not as an end in itself but rather as work that could and should guide policy formation and operations in intercollegiate athletics.

\section{Jay Coakley's Main Points}

In the first portion of his talk, Jay Coakley discussed a number of factors that reduce the likelihood of quality scholarship in intercollegiate athletics, and he then moved on to suggest strategies that might be employed to overcome these conditions.

Jay's list of constraints or inhibitors could be summarized as follows:

1. People who have the data don't much want to be studied;

2. People who would do the research that Jay would like to see aren't drawn to the integration of mind-body issues that should, he believes, be addressed;

The author is a Faculty Athletics Representative, Hettleman Professor of Business, and Executive Director, The University of North Carolina at Chapel Hill, Chapel Hill, NC. 
3. People who like intercollegiate athletics pretty much as is are not likely to welcome critical, objective analysis of the structure and culture involved;

4. People who now sponsor and conduct some inquiry from within intercollegiate athletics (i.e., the NCAA) are unintentional inhibitors of the research that Jay would like to see; and

5. People who would do the research have other scholarly opportunities that entail less risk and at least as much reward (hence, the last portion of the title of Jay's presentation).

This list invites the summary observation that this doesn't appear to be very inviting turf for nontenured faculty.

Jay then moved on to suggest strategies that might be employed in the face of these conditions (which I would be inclined to call demotivators, rather than constraints). He suggested that we should

1. Institutionalize the dissemination to faculty of information about athletics,

2. Provide research grants,

3. Commission brainstorming and focus groups to define a research agenda, and

4. Study the experiences of members of academia who have experienced negative consequences when they have raised issues about athletics (whistle blowing).

Let's return to this list shortly. Before doing that, however, I would like to offer some experience-based observations about the NCAA in a context to which Jay referred.

\section{The NCAA as Producer of Research on Intercollegiate Athletics}

For a period of time now approaching 10 years, I have been a participant in successive stages of the NCAA Division I academic reform initiative. This work has spanned the efforts that have produced a three-part structure, the purpose of which is to produce improved academic performance (i.e., better graduation results) in intercollegiate athletics, specifically in certain high-profile sports. This work has been mandated by the NCAA Board of Directors, who sought improved academic performance but without disparate impact on ethnic minorities. The resulting system, called the NCAA Academic Performance Program, consists of new initial eligibility standards and progress-toward-degree requirements, new metrics to track performance, and new consequences linked to results on these new metrics. Although some small portions of the design work for this system are still under way, the system is substantially complete and is more than 4 years into implementation. Design and implementation are being overseen by the NCAA Committee on Academic Performance, chaired by Dr. Walter Harrison, President of the University of Hartford, reporting ultimately to the Division I Board of Directors.

The work that produced this system built on a body of NCAA-sponsored, applied research. It has been done by groups of faculty athletics representatives and athletic administrators representing the member institutions of the NCAA. These groups made recommendations through the NCAA legislative process 
that culminated with adoption by the Division I Board of Directors. To produce data-based decisions, this work has relied on the NCAA Research Staff for the gathering and analysis of relevant data at every stage. The Research Staff has been, in turn, supported by a consultant (Professor Jack McArdle of the University of Southern California), and their work has been reviewed regularly by the Data Analysis Research Network, a group of academic researchers. The point here is that although this work has not resulted in the typical articles appearing in refereed journals, the work has been subjected to layers of review of a comparable nature. This three-layer approach is the foundation on which many of the policy decisions have been based.

A more recent effort of the NCAA Research Staff has been work on the responses to two surveys that were conducted during 2006-2007. One survey was conducted with current student-athletes (GOALS), and the second survey sought information from a group of former student-athletes who were 8 years beyond completion of their competitive eligibility (SCORES). These data are still being explored for the insights that they can offer to intercollegiate athletics, but preliminary indications suggest that these databases will be a rich source of insight that could be useful to the membership and its policy makers.

\section{Jay Coakley's Proposed Strategies: Two Related Examples}

Jay offered some constructive thoughts for the successful development of a stream of quality scholarship focused on intercollegiate athletics. We can't know in advance whether these strategies will be successful. I think his ideas have promise, however, and here I offer two examples in support of that view. One example is an activity in which I participated directly. The second is a scenario that I have observed.

\section{Corporate America, International Competition, and Quality Improvement}

In the 1960s and 1970s, United States manufacturing companies began to lose market share to international competition, primarily from Japan. The first inroads were in basic industries (e.g., steel), but they progressed into durable goods, reached consumer electronics, and eventually affected some service industries.

During the 1980s, selected U.S. companies identified a body of knowledge, tools, techniques, and practices that helped to slow or reverse these losses. Indeed, Xerox Corporation, manufacturer of copiers, was the first U.S. firm to regain market share that had been lost in this competition. The senior executives who led that successful effort in the 1980s attribute the success to their systematic efforts, over a period of years, to improve product and service quality, to gather and use customer feedback for improvement, and to remove waste and error from their work processes.

In 1987 the U.S. Congress enacted the Malcolm Baldrige National Quality Award to (a) draw attention to quality as a competitive issue; (b) recognize achievements of companies that were successful in improving quality, market share, and financial performance; and (c) promote sharing of successful practices. Over a period of approximately 10 years, I participated in this process as an examiner, 
senior examiner, judge, and eventually member of the Board of Overseers (and chair for 2 years) for this award. This gave me a valuable vantage point from which to observe the relationship between the corporate and academic worlds.

In 1989 Xerox Corporation, then a winner of the Baldrige Award, along with several corporate cosponsors, hosted a forum to which they invited faculty from a number of leading MBA programs in the United States. Their message was straightforward. The corporate world needed more MBA graduates who understood the concepts, tools, and techniques of systematic quality improvement. They wanted more emphasis on this topic in the MBA curricula.

The early dialog at the first forum was guarded, as if the academics were responding that, "You might have discovered something that works in practice, but we're not sure that it works in theory." The message really was that the path to the curriculum leads through research. A central issue in that dialog was the need to separate anecdotes from evidence-based conclusions that could be introduced in curricula.

That first and the succeeding forums in the following years produced an action plan that had a close resemblance to Jay Coakley's strategies. The academics proposed (a) compilation of a comprehensive research bibliography, (b) joint academic-corporate discussions to formulate a relevant research agenda, and (c) creation of a mechanism for research grants. The proposed preliminary work was done. In addition, through collaboration of corporate contributors and the National Science Foundation, a new research track was created that used the National Science Foundation auspices and infrastructure for receipt and evaluation of research proposals. A number of corporations joined efforts to create a pool of contributed funds to support the proposals that were approved for funding.

Research was stimulated, and many MBA curricula developed offerings on customer satisfaction and quality improvement. Thus, I would argue that this is one case, admittedly in a field different from intercollegiate athletics, of a measure of success employing three of the four pieces of Jay's proposed strategy for stimulating research.

\section{An Example From Public Policy}

The second example is about this country's history with tobacco and smoking over that past 50 years or so, but with specific reference to the way in which this story has developed in the state of North Carolina and at the University of North Carolina (UNC) at Chapel Hill.

As a reference point, we all know that the environment of the 1940s and 1950s was one in which smoking was widely accepted in our society. The Surgeon General's warning that became required on packaging for tobacco products did not come easily or without controversy. In the early 1970s I can recall that a research team in the School of Public Health at UNC-Chapel Hill proposed some research related to tobacco use that was actively discouraged by a tobacco company that operated in the state. The research was also questioned by some members of the state legislature. It might be of interest to note that at that time, smoking while the legislature was in session was commonplace.

Much of the national story since that time is well known. It involved study (research) of the causal link between smoking and cancer. In the 1990s, selected 
buildings on the UNC-Chapel Hill campus began to go smoke free. We all know about the class action suits and the tobacco settlement.

Effective January 1, 2008, UNC-Chapel Hill became a smoke-free campus. Smoking within $100 \mathrm{ft}$ of campus buildings is prohibited. In all honesty, compliance is less than perfect, but the policy alone represents significant progress. State government buildings have also gone smoke free.

My point might be obvious, but let me state it, nonetheless. These issues have many points of intersection with Jay's list of constraints or inhibitors regarding quality research. The progress that has been made required, and eventually produced, research on which policy positions could be based. The interactions among research, policy, and implementation eventually produced results that 30 years ago would have seemed improbable, at best.

\section{Conclusion}

To tie these various threads together, let me first return to the GOALS and SCORE databases mention previously. The emergence of the Journal of Intercollegiate Sport would seem to provide an excellent outlet for reviewed publication of results that the NCAA Research Staff will extract from those data. The timing could perhaps hardly be better, and the opportunity touches on one of Jay's concerns. He suggested that a scholar considering the prospect of doing research on intercollegiate athletics might be inclined to worry about being scooped or contradicted by work done within the NCAA. One strategy for offsetting this tendency would be for the NCAA to submit results for prompt publication in the Journal of Intercollegiate Sport, or any other appropriate outlet, just as would any other investigator. I have reason to believe that the people involved in the NCAA work would be eager to do just this.

Now let us consider the link between the two examples in the previous section and Jay's four suggested strategies for enhancing research in intercollegiate athletics. Three of the four suggestions are general in scope, but one seems to differ in kind from the other three. I refer here to the suggestion to study the experiences of academics who have experienced negative consequences when they have raised issues about athletics. This seems to be less of a strategy to enhance research than it is a description of one opportunity for a stream of inquiry (among many others) that might be explored by scholars. Whatever the appropriate research paradigm for this work, one challenge would appear to be that of lifting the level of inquiry above that of summarizing complaints so that valid generalizations could be extracted. Nonetheless, careful inquiry along the suggested lines could produce new and interesting insights.

Beyond that suggestion, Jay is essentially saying that we need (at least) three things to facilitate quality research in intercollegiate athletics: help in defining research opportunities over time, support (perhaps both institutional and financial) for the research, and appropriate outlets. The bibliography that is being compiled as a result of this first Colloquium should serve as a foundation for scholars who might wish to consider research opportunities. Next, any system of research grants for work on intercollegiate athletics would surely only increase the motivation for scholars. Finally, the Journal of Intercollegiate Sport is one experiment that 
should be seen as a partial response to the third requirement. This need not be the only outlet, of course, and we will no doubt have to wait 2 or 3 years before we can evaluate whether this journal is a success, but the Journal of Intercollegiate Sport provides a specific, refereed outlet with a clear scope. This might also serve to attract scholarly work to a channel that we know will reach a readership that has reason to be interested in the work.

The challenge of quality scholarship in intercollegiate athletics would appear to have two elements. One is the challenge of identifying research topics that are sufficiently focused to permit findings that will survive appropriate scrutiny. The second is the challenge of completing work that is sufficiently broad in scope to be useful in the formation of policy or as guidance for operations in intercollegiate athletics.

What are the prospects? First, anecdotal evidence from other areas suggests that Jay's proposed strategies, suitably adapted, could contribute to increased research activity in intercollegiate athletics. Second, we are admittedly entering a trial period for the Colloquium and the Journal of Intercollegiate Sport. Finally, the conjunction of these activities would seem to create enhanced opportunity for careful scholarship in intercollegiate athletics that might become a valuable complement to the existing sources of advice that shape policy for intercollegiate athletics. 